Article

\title{
Engineering Characteristics and Environmental Risks of Utilizing Recycled Aluminum Salt Slag and Recycled Concrete as a Sustainable Geomaterial
}

\author{
Youli Lin ${ }^{1}$, Farshid Maghool ${ }^{1}$, Arul Arulrajah ${ }^{1}$ and Suksun Horpibulsuk ${ }^{1,2,3, *(D)}$ \\ 1 Department of Civil and Construction Engineering, Swinburne University of Technology, \\ Melbourne 3122, Australia; youlilin@swin.edu.au (Y.L.); fmaghool@swin.edu.au (F.M.); \\ aarulrajah@swin.edu.au (A.A.) \\ 2 Center of Excellence in Innovation for Sustainable Infrastructure Development, School of Civil Engineering, \\ Suranaree University of Technology, Nakhon Ratchasima 30000, Thailand \\ 3 Academy of Science, Royal Society of Thailand, Bangkok 10300, Thailand \\ * Correspondence: suksun@g.sut.ac.th; Tel.: +66-4422-4322
}

\section{check for} updates

Citation: Lin, Y.; Maghool, F.; Arulrajah, A.; Horpibulsuk, S. Engineering Characteristics and Environmental Risks of Utilizing Recycled Aluminum Salt Slag and Recycled Concrete as a Sustainable Geomaterial. Sustainability 2021, 13, 10633. https://doi.org/10.3390/ su131910633

Academic Editor: Castorina Silva Vieira

Received: 1 September 2021

Accepted: 21 September 2021

Published: 24 September 2021

Publisher's Note: MDPI stays neutral with regard to jurisdictional claims in published maps and institutional affiliations.

Copyright: (c) 2021 by the authors. Licensee MDPI, Basel, Switzerland. This article is an open access article distributed under the terms and conditions of the Creative Commons Attribution (CC BY) license (https:/ / creativecommons.org/licenses/by/ $4.0 /)$.

\begin{abstract}
Recycled aluminum salt slag (RASS) is an industrial by-product generated from the melting of white dross and aluminum scraps during the secondary smelter process. Insufficient knowledge in the aspects of engineering characteristics, and the environmental risks associated with RASS, is the primary barrier to the utilization of RASS as a substitute material for natural quarry materials in the field of geotechnical construction. In this research, comprehensive geotechnical and environmental engineering tests were conducted to evaluate the feasibility of utilizing RASS as a sustainable geomaterial. This was undertaken by comparing the laboratory testing results for RASS with a wellknown recycled material, namely recycled concrete aggregate (RCA), and the relevant specifications set forth by the local road authority. The geotechnical engineering assessment included particle size distribution, flakiness index, organic content, $\mathrm{pH}$, particle density, water absorption, modified Proctor compaction, aggregate impact value, Los Angeles (LA) abrasion, hydraulic conductivity, and California bearing ratio (CBR). The CBR results of the RASS samples satisfied the minimum CBR value $(>80 \%)$ for usage as pavement subbase material in road construction. In addition, the repeated load triaxial (RLT) tests were carried out on the RASS samples to assess the response of the RASS under cyclic loading conditions. Furthermore, a range of chemical tests, consisting of leaching and polycyclic aromatic hydrocarbon tests, were also performed on the RASS to address the environmental concerns. Comparing the chemical test results with the environmental protection authorities' guidelines provided satisfactory evidence that RASS will not pose any environmental and health issues throughout its service life as a geotechnical construction material.
\end{abstract}

Keywords: recycled aluminum salt slag; recycled materials; resilient modulus; leachate analysis; pavement geotechnics

\section{Introduction}

The sophisticated lifestyles and urbanization have dramatically increased the generation of waste materials from both the construction and industrial sectors. Recycling of waste materials, produced by construction and industrial activities, is becoming one of the key strategies globally in waste reduction, landfill avoidance, and to facilitate the movement towards sustainable development [1]. Many countries, such as Australia and New Zealand, are encouraging the recycling and reutilizing of waste materials by implementing a landfill levy on the disposal of waste to alleviate the pressure on natural resources and the shortage of landfill sites [2]. Over the last few years, many attempts have been made to utilize construction and demolition (C\&D) waste materials, such as recycled concrete aggregate, crushed brick, reclaimed asphalt pavement, and waste rock, as substitution materials of virgin quarry materials in various geotechnical applications: 
for instance, road, embankment, pipe bedding, and ground improvements in the aspects of soil stabilization and the construction of stone columns [3-7]. Research on stockpiled industrial by-products, in particular, granulated blast furnace slag, electric arc furnace slag, ladle furnace slag, copper slag, and gypsum-based waste, have also garnered significant interest in the past years, used as supplementary or substitution materials in construction, concrete production, and pavement applications [8-11]. Yi et al. [8] compared carbide slag-activated ground granulated blast furnace slag (CS-GGBS) with Portland cement (PC), for use in soft clay stabilization, and reported that the unconfined compressive strength of the optimum CS-GGBS blend was twice as high as the corresponding PC stabilized clay, demonstrating the feasibility of utilizing CS-GGBS for the replacement of PC in soft clay stabilization. Imteaz et al. [9] conducted a series of geotechnical and environmental tests to evaluate the viability of utilizing gypsum-based waste in geotechnical applications. The results of the study found that gypsum-based plasterboard waste satisfied the engineering requirements and caused no environmental impacts for usage as road subgrade and pipe bedding material. Maghool et al. [10] carried out a study to investigate the shear strength and stiffness of electric arc furnace slag (EAFS), ladle furnace slag (LFS), and their mixture (50\% LFS $+50 \%$ EAFS). The study results demonstrated that both LFS and the mixture of (50\% LFS + 50\% EAFS) exhibit high friction angles similar to that of natural quarry materials. The test results of California bearing ratio and resilient modulus have also met the requirements for usage as a geomaterial in road applications, such as pavement base and subbase. Prem et al. [11] performed research to evaluate the influence of substituting 100\% natural sand with high volume copper slag in concrete and reported that concrete samples on full replacement of natural sand with copper slag improved the compressive/flexural strength, toughness, and energy-absorbing capacity compared to the concrete made with river sand. In addition, the durability performance, in terms of chloride penetration and water absorption, remains unaffected after substituting $100 \%$ of natural sand with copper slag in concrete.

Aluminum is a non-ferrous metal, an indispensable raw material used for making a wide range of metallic products. According to the data provided by the International Aluminium Institute Statistics, about 65,000 thousand tons of aluminum yielded from primary aluminum production in 2020 [12]. During the aluminum making process, three types of by-products are generated at various stages, including white dross, very rich in aluminum content ranging from $40-80 \%$ produced during the primary aluminum process and downstream ingot smelting operations. Black dross, also known as aluminum salt slag, contains a lower aluminum content, typically $5-20 \%$ generated from the melting of white dross and aluminum scraps during the secondary smelters process with the presence of a salt flux composed of potassium chloride $(\mathrm{KCl})$, sodium chloride $(\mathrm{NaCl})$, and a small amount of fluorides. Non-metallic products are created from the tertiary smelters during the water leaching process of black dross/aluminum salt slag [13]. Depending on the type of furnace used and the manufacturing technique, between 300 to $600 \mathrm{~kg}$ of aluminum slat slag is generated for the production of one ton of aluminum [14]. However, about 95\% of aluminum salt slag was stockpiled in landfill, leading to extensive pressure on landfill sites and severe environmental concerns [15]. In the past, the use of aluminum salt slag as a substitute material to natural aggregates, in the field of civil construction, was not so favorable. It is because the aluminum slat slag is prone to leaching chlorides and releases unpleasant odorous gases such as methane, ammonia, phosphide, and hydrogen sulphide when in contact with water [16]. However, with the improvement in aluminum production technology, black dross/aluminum salt slag can be treated by a wet/dry separation process, followed by water leaching and filtering to wash away and separate the soluble salt flux from insoluble oxides. Harmful gases are eliminated through conveyed and burnt odorous gases (typically hydrogen, ammonia, phosphine, and methane), generated during the leaching and dissolution process in a combustor, consequently transforming the harmful gases into water and inert gases. Finally, the separated salt flux is converted into a useable form through evaporation and crystallization processes. Karvelas et al. [17] conducted 
an economic and technical assessment of recycling systems for black dross/aluminum salt slag in the secondary aluminum industry. The study found that, if the presence of aluminum content in the black dross/aluminum salt slag is higher than $10 \%$, the net revenues from the recovered aluminum and salts are sufficient to cover the operating and capital cost of the wet/dry separation process [17]. By considering the scarcity of landfill sites, rapid increase in landfill levy, along with all the environmental concerns, the treatment for such aluminum industrial by-products that convert aluminum waste into a useable form is rewarding and worth performing to improve sustainability in the aluminum industry. As a result, the aluminum salt slag treated by wet/dry separation technique exhibits very low chloride content, harmful gases are eliminated, and thus, it is safe to be utilized as a civil construction material and by the cement industry [14].

To date, some studies have initiated the utilization of recycled aluminum salt slag (RASS) as a supplementary material for making cement composites. A number of recent studies have demonstrated that incorporating RASS as an ingredient in mortar and concrete, up to $15 \%$, caused no negative impact on the mechanical performance of the cement composites; the addition of RASS in mortar and concrete can also enhance the durability of the cement composites in terms of controlling microstructural cracks, improving abrasion, and corrosion resistivity [15,16,18-22]. Dunster et al. [23] stated that black dross/RASS with smaller grain size $(<700 \mu \mathrm{m})$ had the potential to be used as filler aggregate in asphalt to enhance the hardness, abrasion, and skid resistance of the pavement. Similarly, LópezAlonso et al. [24] demonstrated the feasibility of using aluminum waste, blended with recycled aggregates, as a road construction material to enhance the resistance properties and long-term mechanical behavior of the unbound road layer. Furthermore, several studies have utilized aluminum waste in stabilizing expansive soil and tropical lateritic soil. The results of the studies indicated that infusing aluminum waste in the soil specimen could reduce the swelling and shrinkage behavior of the expansive soil and enhance the bearing capacity of the tropical lateritic soil notably $[25,26]$.

Over the years, several million tons of RASS were produced annually, and about 95\% of them were sent to landfill instead of being recycled and reused [16]. This is believed to be the consequence of insufficient knowledge and understanding of RASS in terms of its engineering and environmental properties. Research on the utilization of RASS as a geomaterial is still very limited. There have been no known studies thoroughly investigating the geotechnical and geo-environmental characteristics of the RASS and its potential to be utilized as an alternative source of aggregate in geotechnical applications. To fulfil the current research gap, comprehensive geotechnical and environmental engineering tests were conducted on RASS to assess the feasibility of utilizing RASS as a sustainable geomaterial. The usage of RASS, as a geomaterial in civil construction, can add value to the aluminum industrial waste by-products, reduce the cost for landfilling, and lower the usage of raw quarry materials and the carbon footprint of future civil infrastructure projects.

\section{Materials and Methods}

\subsection{Geotechnical Engineering Tests}

The materials used in this research were comprised of recycled aluminum salt slag (RASS) and recycled concrete aggregate (RCA), one of the well-known recycled materials available in the market. RASS was derived from a major aluminum manufacturer located in Melbourne, Australia. RCA is a by-product of (C\&D) activities of concrete structures. It is produced by crushing large concrete chunks into aggregates of various sizes depending on the field application. The RCA used in this research was sourced from a recycling plant in Melbourne, Australia and had a maximum particle size of $20 \mathrm{~mm}$. The RCA was comprises of 1-2 wt\% of crushed brick, reclaimed crushed asphalt pavement aggregates, and a very small fraction $(<1 \mathrm{wt} \%)$ of other foreign materials such as glass, wood, plastic, and gypsum.

An extensive suite of laboratory tests was conducted to assess the geotechnical and geo-environmental characteristics of RASS and RCA as per relevant international stan- 
dards, including the American Society for Testing Materials (ASTM), Australian Standards (AS), and British Standards (BS). The experimental program included particle size distribution, unified soil classification, flakiness index, organic content, $\mathrm{pH}$, particle density, water absorption, modified Proctor compaction, aggregate impact value, Los Angeles (LA) abrasion, hydraulic conductivity, California bearing ratio (CBR), resilient modulus $\left(\mathrm{M}_{\mathrm{R}}\right)$, as well as a range of chemical and environmental tests. The morphology studies of RASS and RCA were also performed by employing scanning electron microscopy (SEM). The testing results of RASS and RCA were compared to provide a synthetic examination on the viability of utilizing RASS as a sustainable geomaterial.

Necessary precautions were taken to obtain RASS and RCA samples from different stockpiles, as per the procedures mentioned in ASTM D75 [27]. The collected materials were dried in an oven at the standard drying temperature $\left(100 \pm 5^{\circ} \mathrm{C}\right)$ for $24 \mathrm{~h}$ to remove the natural moisture content. The oven-dried materials were then thoroughly mixed, split, sieved through a $20 \mathrm{~mm}$ sieve, and riffled by different sizes of riffle splitter to prepare the representative samples for further laboratory testing.

Particle size distribution (PSD) test was carried out on RASS and RCA as per AS 1141.11 [28]. Since both RASS and RCA samples contained fine fraction of less than $5 \%$, the hydrometer test was not performed further. The particle breakage of the material was also assessed through conducting additional PSD tests on the RASS and RCA samples, which underwent the modified Proctor compaction effort, and the PSD curves before and after the compaction were plotted for comparison and analysis.

Unified Soil Classification System (USCS) was employed for the classification of the recycled materials according to the sieve analysis results [29]. A flakiness index test was implemented to examine the particle shape of the recycled materials, in line with the procedures outlined in BS 812-105 [30]. The percentage of organic content present in RASS and RCA were determined using the loss of ignition methods described in ASTM D2974 [31], and an electrometric method was utilized to measure the $\mathrm{pH}$ value of both materials as per AS 1289.4.3.1 [32]. Triplicate samples of both recycled materials were prepared and tested for their flakiness index, organic content, and $\mathrm{pH}$ value to minimize error margins.

The particle density and water absorption of RASS and RCA samples for both fine and coarse fraction were established in line with the steps described in AS 1141.5 [33] and AS 1141.6.1 [34]. Three samples for each recycled material were prepared for the particle density and water absorption tests, and the average values of three tests were adopted as final results. Modified Proctor compaction tests were performed to investigate the relationship between the moisture content and dry density of the samples, according to the AS 1289.5.2.1 [35]. By following the procedures outlined in AS 1289.5.2.1 [35], the samples were compacted in five layers in a steel mold with an internal diameter of $105 \mathrm{~mm}$ and $115 \mathrm{~mm}$ in height. An automatic Proctor compactor was employed to apply constant compaction energy to ensure each layer is evenly compacted when making the samples. Each layer was compacted with a $4.9 \mathrm{~kg}$ rammer falling freely from a height of $450 \mathrm{~mm}$ by 25 blows. The optimum moisture content (OMC) and the maximum dry density (MDD) were determined by plotting the compaction curves accordingly.

The aggregate impact value (AIV) of the samples was measured by an impact testing machine to identify the resistance of the RASS and RCA aggregates subject to sudden shock as per BS 812-112 [36]. Los Angeles (LA) abrasion tests were conducted to assess the resistance to degradation performance of RASS and RCA aggregates by employing the Los Angeles testing machine in accordance with ASTM C131 [37]. Hydraulic conductivity tests were performed to confirm the coefficient of permeability for the flow of water through a remolded specimen, according to AS 1289.6.7.1 [38] and AS 1289.6.7.2 [39], in which a constant head method was selected for a more permeable material (RASS), and a falling head method was adopted for RCA sample with an expected hydraulic conductivity between $10^{-7}$ to $10^{-9} \mathrm{~m} / \mathrm{s}$. Triplicate samples of both recycled materials were prepared for 
AIV, LA abrasion, and hydraulic conductivity tests to ensure the repeatability and accuracy of the results.

Three samples for each recycled material were prepared in line with the procedures detailed in the ASTM D1883 [40] for conducting the California bearing ratio (CBR) test. The samples were compacted by the modified Proctor compaction effort at the OMC to achieve the targeted MDD of $98 \%$. The compacted samples were immersed in a water tank for $96 \mathrm{~h}$ to simulate the worst-case scenario of the field conditions. A mechanical dial gauge was installed on top of the CBR mold to measure the swelling of each material during the soaking period, and the penetration tests were carried out on the samples after being soaked for 4 days at a rate of $1 \mathrm{~mm} / \mathrm{min}$.

The repeated load triaxial (RLT) test was undertaken to measure the resilient modulus $\left(\mathrm{M}_{\mathrm{R}}\right)$ of RASS and RCA, as per the procedures outlined in AASHTO T 307 [41] for unbound granular base/subbase materials. Triplicate samples were prepared using a split mold with an internal diameter of $100 \pm 1 \mathrm{~mm}$ and $200 \pm 1 \mathrm{~mm}$ in height. An automatic Proctor compactor was used to apply constant Proctor compaction energy of 25 blows per layer in a total of 8 layers at the OMC to attain the targeted MDD of $98 \%$. Since the RASS sample contains insufficient fine fraction and cohesion among its particles, the compacted sample was not able to retain its shape and slumped on the removal of the split mold. A vacuum pump was employed to produce vacuum pressure inside the membrane to hold the sample together during the assembling of the triaxial chamber. The vacuum pressure inside the sample was then released after initiating the RLT test, as the applied air confining pressure inside the chamber will take place and hold the sample together during the testing period. According to the RLT testing protocol for unbound granular base/subbase materials, outlined in AASHTO T 307 [41], the testing sample was subject to five different confining pressures and 15 load sequences. For each load sequence, 100 repetitions of cyclic load were applied on the sample with repeated cycles of a Haversine-shaped loading pulse of $0.1 \mathrm{~s}$ and a resting period of $0.9 \mathrm{~s}$ to simulate the dynamic traffic loads acting on the unbound granular base/subbase materials.

\subsection{Geo-Environmental Tests}

Apart from the above-mentioned tests evaluating the geotechnical properties of the RASS sample, the chemical characteristics of the RASS, with regard to the environmental risks and health hazards, are crucial in consideration of utilizing RASS as a geomaterial. A total contaminant and leachate concentration test, to determine the possible existence of contaminant constituents such as heavy metals and polycyclic aromatic hydrocarbons, were conducted in accordance with the AS 4439.3-1997 [42]. For the preparation of leachate, the procedures detailed in the AS 4439.3-1997 [42] were followed. A marginally acidic and alkaline leaching fluid, with $\mathrm{pH}$ values of 5.0 and 9.2, were employed as leachate for the test. The results from the total contaminant and leachate concentration tests of the RASS sample were then compared with the requirements specified by the Environmental Protection Authority of Victoria (EPA Victoria) [43,44] and the Environmental Protect Agency of Washington (EPA USA) [45] to ascertain the environmental impacts of using RASS as a sustainable geomaterial.

\section{Results and Discussion}

\subsection{Morphology of RASS and RCA}

The physical appearance of as-received RASS and RCA, with maximum grain size smaller than $20 \mathrm{~mm}$, is shown in Figure 1a,d, respectively. The RASS is a greyish and silvery color as illustrated in Figure 1a, whereas the RCA is of a brownish color depicted in Figure 1d. Different types of impurities were present in both recycled materials, of which wooden particles and some unmelted aluminum products, such as nails, screws and residual parts of the beverage cans were found in the RASS sample. Natural aggregate, crushed brick, timber, and plastic were discovered in the RCA sample. For a better understanding of the particle shapes, and microstructure of RASS and RCA, the SEM 
images were also taken at a magnification of $100 \mu \mathrm{m}$ and $20 \mu \mathrm{m}$ to further investigate the morphology of both recycled materials. SEM image in Figure 1b shows that the RASS particles appear to be angular and irregular in shape. Some flaky particles are also observed in the RASS sample. Upon closer inspection of Figure 1c, the surface of RASS particles is reasonably rough. On the other hand, Figure le demonstrates that the RCA particles are more rounded and oval in shape, and the surface is found to be cratered. Additionally, noticeable microcracks are observed on the RCA particles at higher magnification, as depicted in Figure 1f, and the formation of the microcracks could be mainly attributed to the crushing process of the concrete blocks.

(a)
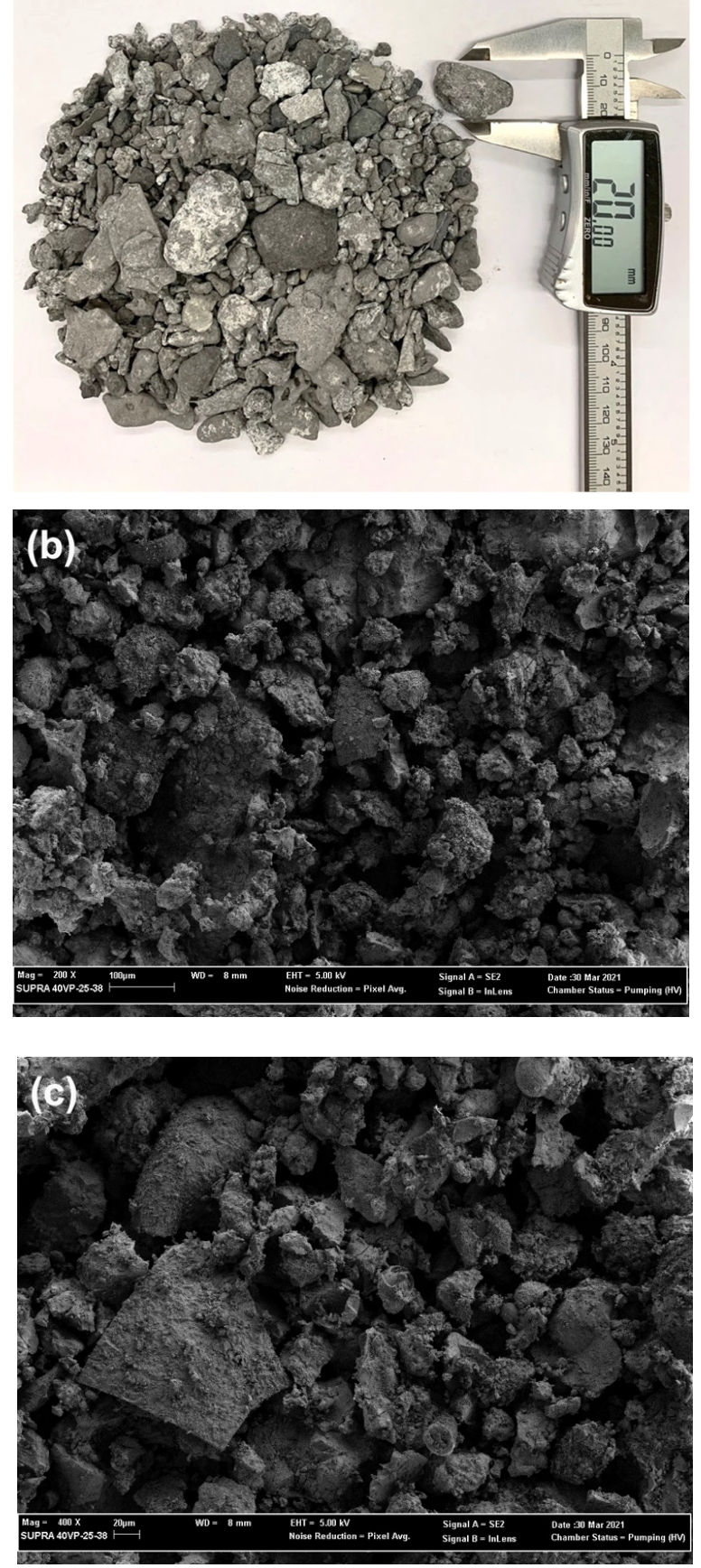

(d)
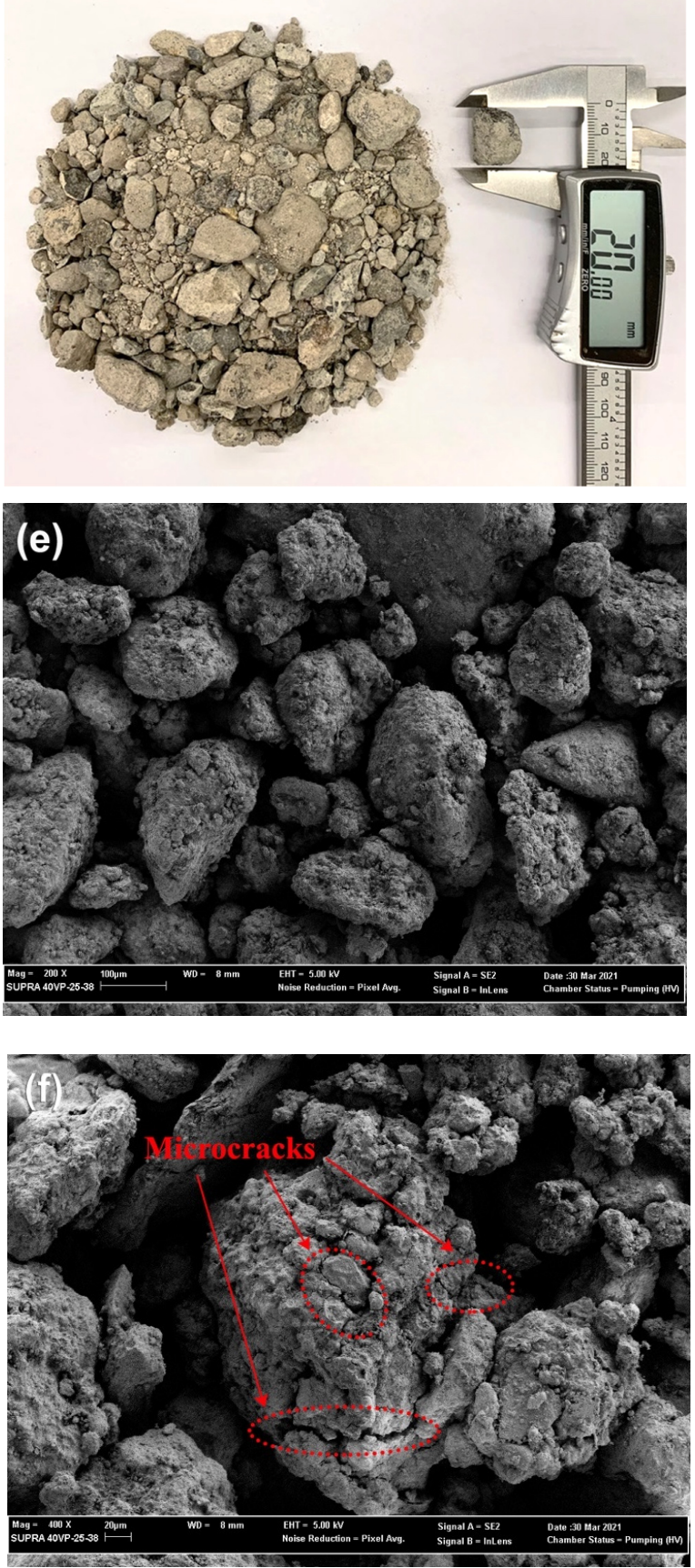

Figure 1. Physical appearance and SEM images of RASS and RCA at $100 \mu \mathrm{m}$ and $20 \mu \mathrm{m}$ magnification: (a) RASS actual

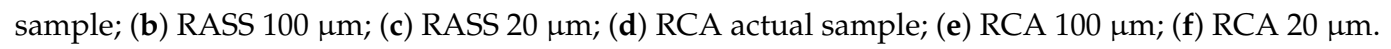




\subsection{Geotechnical Characteristics}

\subsubsection{Particle Size Distribution}

The geotechnical characteristics of RASS and RCA were evaluated through undertaking a series of laboratory assessments in accordance with relevant international standards (ASTM, Australian, and British). The testing results of RASS and RCA are tabulated in Table 1. Figure 2 illustrates the PSD curves of RASS and RCA samples before and after applying modified Proctor compaction effort. The gradation curves of RCA lay well within the grading specification recommended by the local road authority for unbound subbase materials [46], whereas the PSD curves of RASS are off the subbase lower limit due to the lack of fine fraction in the sample. According to the USCS, the RASS and RCA sample were classified as GP and GW, the percentage of fine, sand, and coarse fraction were also computed and shown in Table 1. By comparing the gradation curves before and after the modified compaction effort, the (after compaction) gradation curve of RCA shifts upward, indicating the degradation and particle breakage of the granular material subject to impact loading. The reason can be ascribed to the formation of microcracks on the RCA granular material during the crushing process of the concrete blocks (illustrated in Figure 1f). The presence of microcracks weaken the stiffness of RCA particles and make RCA more susceptible to degradation under shock loading. Interestingly, no significant alteration was observed for the gradation curve of the RASS sample after the compaction, which indicates superior stiffness and excellent performance on resistance to degradation of RASS material.

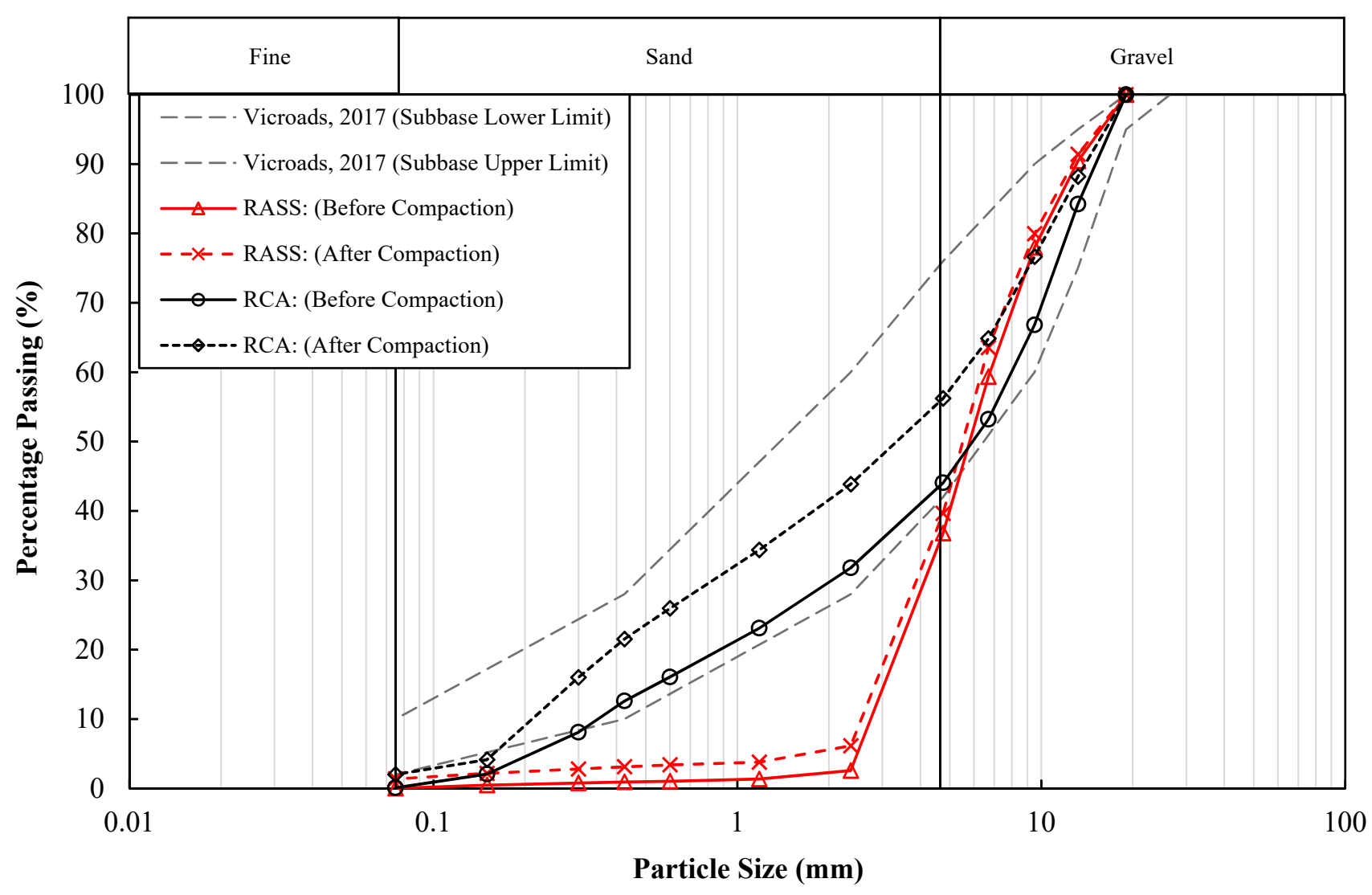

Figure 2. Particle size distribution curves of RASS and RCA. 
Table 1. Geotechnical Characteristics of RASS and RCA.

\begin{tabular}{ccc}
\hline Geotechnical Parameters & RASS & RCA \\
\hline Fine content: $<0.075 \mathrm{~mm}(\%)$ & 1.61 & 3.01 \\
Sand content: $0.075-4.75 \mathrm{~mm}(\%)$ & 36.18 & 42.67 \\
Gravel content: $>4.75 \mathrm{~mm}(\%)$ & 62.20 & 54.31 \\
Coefficient of uniformity $\left(\mathrm{C}_{\mathrm{u}}\right)$ & 2.59 & 25.71 \\
Coefficient of curvature $\left(\mathrm{C}_{\mathrm{c}}\right)$ & 0.93 & 1.54 \\
Soil classification (USCS) & $\mathrm{GP}$ & $\mathrm{GW}$ \\
OMC $(\%)$ modified Proctor compaction & 6.6 & 10.6 \\
MDD (Mg/m $\mathrm{m}^{3}$ - modified Proctor compaction & 1.66 & 1.94 \\
Particle density-coarse fraction $\left(\mathrm{Mg} / \mathrm{m}^{3}\right)$ & 2.83 & 2.72 \\
Particle density-fine fraction $\left(\mathrm{Mg} / \mathrm{m}^{3}\right)$ & 2.95 & 2.85 \\
Water absorption-coarse fraction $(\%)$ & 3.29 & 6.49 \\
Water absorption-fine fraction $(\%)$ & 4.75 & 9.2 \\
Organic content $(\%)$ & 1.91 & 3.51 \\
pH & 8.01 & 12.39 \\
Flakiness index & 32.63 & 8.81 \\
LA abrasion loss $(\%)$ & 6.23 & 31.77 \\
Hydraulic conductivity $(\mathrm{m} / \mathrm{s})$ & $4.16 \times 10^{-6}$ & $4.16 \times 10^{-8}$ \\
Aggregate impact value $(\%)$ & 2.71 & 32.36 \\
CBR range $(\%)$ & $91-106$ & $189-220$ \\
CBR swell $(\%)$ & $\approx 0$ & $\approx 0$ \\
Resilient modulus, $\mathrm{M}_{\mathrm{R}}$ range $(\mathrm{MPa})$ & $88.5-288.1$ & $201.5-402.0$ \\
\hline
\end{tabular}

\subsubsection{Particle Density, Water Absorption, $\mathrm{pH}$ and Organic Content}

The particle density and water absorption test results for both fine and coarse fraction, of RASS and RCA, are shown in Table 1. The apparent density of RASS for both coarse $\left(2.83 \mathrm{Mg} / \mathrm{m}^{3}\right)$ and fine $\left(2.95 \mathrm{Mg} / \mathrm{m}^{3}\right)$ fraction is slightly higher than that of RCA $\left(2.72 \mathrm{Mg} / \mathrm{m}^{3}\right.$ for coarse and $2.85 \mathrm{Mg} / \mathrm{m}^{3}$ for fine fraction). The slightly lower particle density of RCA can mainly be attributed to the presence of a small fraction of low-density materials such as timber, plastic, and gypsum. As RCA is derived from construction and demolition site, such low-density materials including timber, plastic, and gypsum have a higher chance to be mixed with RCA during the demolishing, recycling, and crushing process. Interestingly, the percentage of water absorption of RCA is almost twice as high as that of the RASS for both fine and coarse fractions, indicating a relatively lower water absorption characteristic of RASS material. In addition, the water absorption of the fine fraction of both materials was found to be higher than that of the coarse fraction. The reason can be ascribed to the larger specific surface area of fine particles that absorbs more water to wet their surface compared to the coarse ones. The average $\mathrm{pH}$ value of the RCA sample was found to be 12.39 , which is higher than the $\mathrm{pH}$ value of RASS $(\mathrm{pH} \approx 8)$, as the concrete is alkaline by nature. The percentage of organic content of both materials are manifested in Table 1. Wooden particles and other impurities were observed in both materials during the preparation of samples for the organic content test. Since the RCA is derived from the demolition wastes, there is a higher chance for the impurities, such as wood and plastic, to be mixed with the RCA during the demolishing, recycling, and crushing process, which explains the reason for the greater percentage of organic content in comparison with RASS.

\subsubsection{Aggregate Impact Value and LA Abrasion Loss}

The results of LA abrasion loss and aggregate impact value (AIV) of RASS and RCA are depicted in Table 1. A lower percentage of LA abrasion loss and AIV is obtained for the RASS (6.23\% and $2.71 \%$ ), whereas higher values were acquired for the RCA ( $31.77 \%$ and $32.36 \%$ ). The lower percentage of LA abrasion loss and AIV indicates an excellent stiffness and better resistance to degradation properties of the RASS. However, the hardness of RCA particles is lower than that of the RASS, based on the experimental outcomes of 
LA abrasion loss and AIV. The RCA particles are more susceptible to degradation under the action of attrition and impact, attributed to the presence of microcracks developed during the crushing process (shown in Figure 1f), and consequently weaken the structural integrity of RCA particles. The results of LA abrasion loss and AIV are also consistent with the findings from the sieving analysis discussed previously, revealing the same intrinsic properties of both materials. Nevertheless, both recycled materials satisfy the limits (LA abrasion loss $<40 \%$ ) recommended in VicRoads [46] for pavement subbase applications.

\subsubsection{Modified Proctor Compaction}

Figure 3 illustrates the modified Proctor compaction curves of RASS and RCA. Typical bell shape compaction curves are attained for both materials. Since the OMC of a material is typically influenced by its water absorption characteristic, which explains the reason for a lower OMC value obtained for the RASS compared to the RCA. Additionally, well-graded RCA also contains a greater amount of fine particles, with larger specific surface areas to absorb more water than a coarser material (RASS), and subsequently leading to a higher OMC value as a result. Despite the fact that RASS has a slightly higher apparent density than that of RCA, the modified Proctor compaction test results indicated that RASS has a lower MDD value compared to the RCA. The particle breakage of aggregates in RCA is more significant compared to RASS. As discussed in Section 3.2.3, the RCA has a much higher LA abrasion loss and AIV value compared to RASS, which is also consistent with the occurrence of particle breakage observed from the PSD tests (illustrated in Figure 2) for the RCA sample that underwent the modified Proctor compaction effort. A previous study reported that particle breakage, during the modified Proctor compaction process, can aid the compaction of a material into a denser state [47]. A higher degree of particle breakage of RCA will lead to a denser arrangement in the fabric of RCA compared to RASS, and enhance, contributing a higher MDD value of RCA. Apart from that, the substantial amount of voids retained among the coarse aggregates during the compaction process, due to the poor gradation of RASS, was considered to be another factor that significantly limits the compressibility of the material.

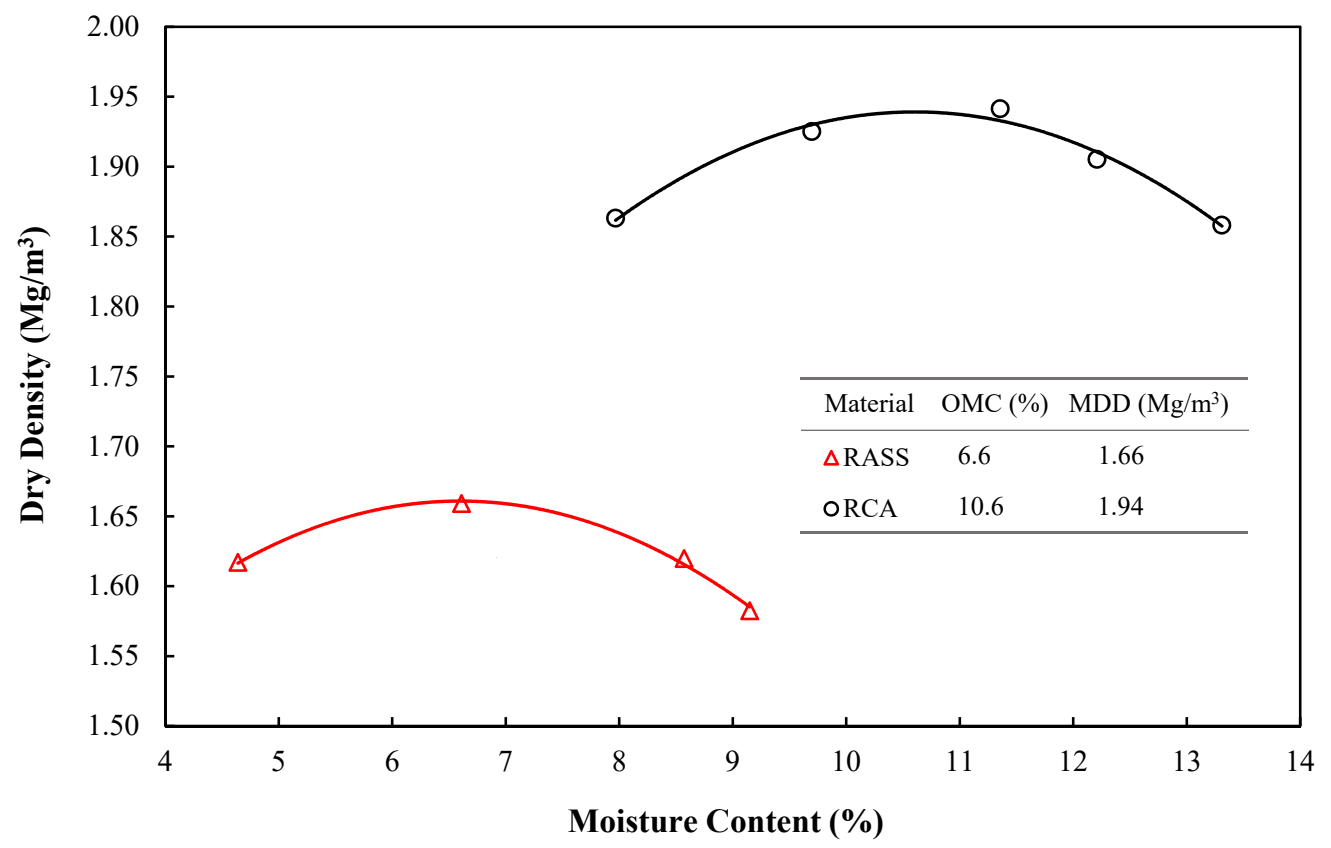

Figure 3. Modified Proctor compaction curves of RASS and RCA. 


\subsubsection{Flakiness Index and Hydraulic Conductivity}

The flakiness index value of RASS was established to be considerably higher than that of the RCA, indicating a more flaky shape of particles present in the RASS sample. The flakiness index values of both recycled materials are still within the maximum limit $(<35)$ specified by the local road authority for usage as a road construction base material [46]. The hydraulic conductivity of both materials was computed and shown in Table 1 . The hydraulic conductivity value of RASS was determined to be higher than that of RCA. The reason can be ascribed to the insufficient fine particles in the RASS sample to fill up the voids among coarser aggregates, eventually leading to high voids ratio, which allows the water to seep through more easily. In contrast, the better compressibility of RCA material, owing to its excellent gradation accompanied by a low void ratio, reduces the water seepage rate notably, hence yielding a lower hydraulic conductivity as a result.

\subsubsection{California Bearing Ratio (CBR)}

Three samples for each material were prepared for the CBR test, and the range of CBR test results for both RASS and RCA are manifested in Table 1. In light of the specifications recommended by the local road authority, a minimum CBR value of $80 \%$ is typically required for a subbase material [46]. The results of the soaked CBR tests suggest that both recycled materials satisfy the minimum CBR value of $80 \%$ for usage as subbase material in road construction. In addition, the swelling behavior was not observed for the RASS and RCA samples during the soaking period. The CBR values of RASS samples are confirmed to be noticeably lower than those of RCA samples. This can be related to the lower MDD value of RASS achieved during the modified Proctor compaction effort, due to the poor gradation of the RASS. As a consequence, the formation of abundant voids inside the RASS samples weaken the particle interlocking performance, reduce the friction between the particles, leading to a poor stress distribution behavior of the RASS samples, and tend to lower the CBR value. The other reason that could contribute to a lower CBR value on the RASS samples can be ascribed to the cohesionless nature of the RASS material to bond the particles together, which also explains the greater CBR value observed on the RCA material with higher cohesion. It is suggested that RASS can be blended with other well-graded high-quality recycled material, such as RCA, to improve its CBR value and widen its applications in road construction.

\subsubsection{Repeated Load Triaxial (RLT)}

The RLT tests were performed on the RASS and RCA samples to simulate the dynamic traffic loads acting on the unbound granular base/subbase materials, under a combination of different confining pressures and deviator stresses. Figure 4 illustrates the $M_{R}$ values of RASS and RCA at each load sequence, accompanied with different confining pressures. Figure 5 demonstrates the influence of various axial stresses on the resilient modulus response of the RASS and RCA samples. According to the RLT results, the $M_{R}$ values of the RASS were found to be lower than those of the RCA. The reason is mainly attributed to the poor gradation of RASS with insufficient fine particles to fill up the voids among the coarser aggregates during the compaction process. This weakens the particle interlocking performance, and the sensitivity of resilient modulus response of the tested granular samples due to the reduction in the contact area between the particles, eventually contributing to lower $\mathrm{M}_{\mathrm{R}}$ values of RASS samples. Additionally, a higher content of flaky-shape particles present in the RASS was considered to be another possible factor leading to lower $M_{R}$ values of the RASS, in comparison with the RCA, that contains a higher portion of rounded particles [48]. However, further investigation is needed to verify this hypothesis. Moreover, the $\mathrm{M}_{\mathrm{R}}$ values of both materials are increased accompanied by an increase in confinement, which is similar to the trend observed in previous studies [49,50]. The reason is due to the fact that the tested samples inside the triaxial chamber became denser and stronger with an increase in confining pressure, thus contributing to greater $M_{R}$ values. Apart from that, both materials also exhibited higher $\mathrm{M}_{\mathrm{R}}$ values when the deviator stress was increased 
under constant confinement. A similar trend was also revealed in previous studies, and the reason for this phenomenon can be owed to the stress hardening behavior on the granular samples, in which the material tends to get stiffer under higher axial stresses. As a consequence, the samples yield lower axial strain, with increments in deviator stress, and achieved higher $\mathrm{M}_{\mathrm{R}}$ values [51,52].

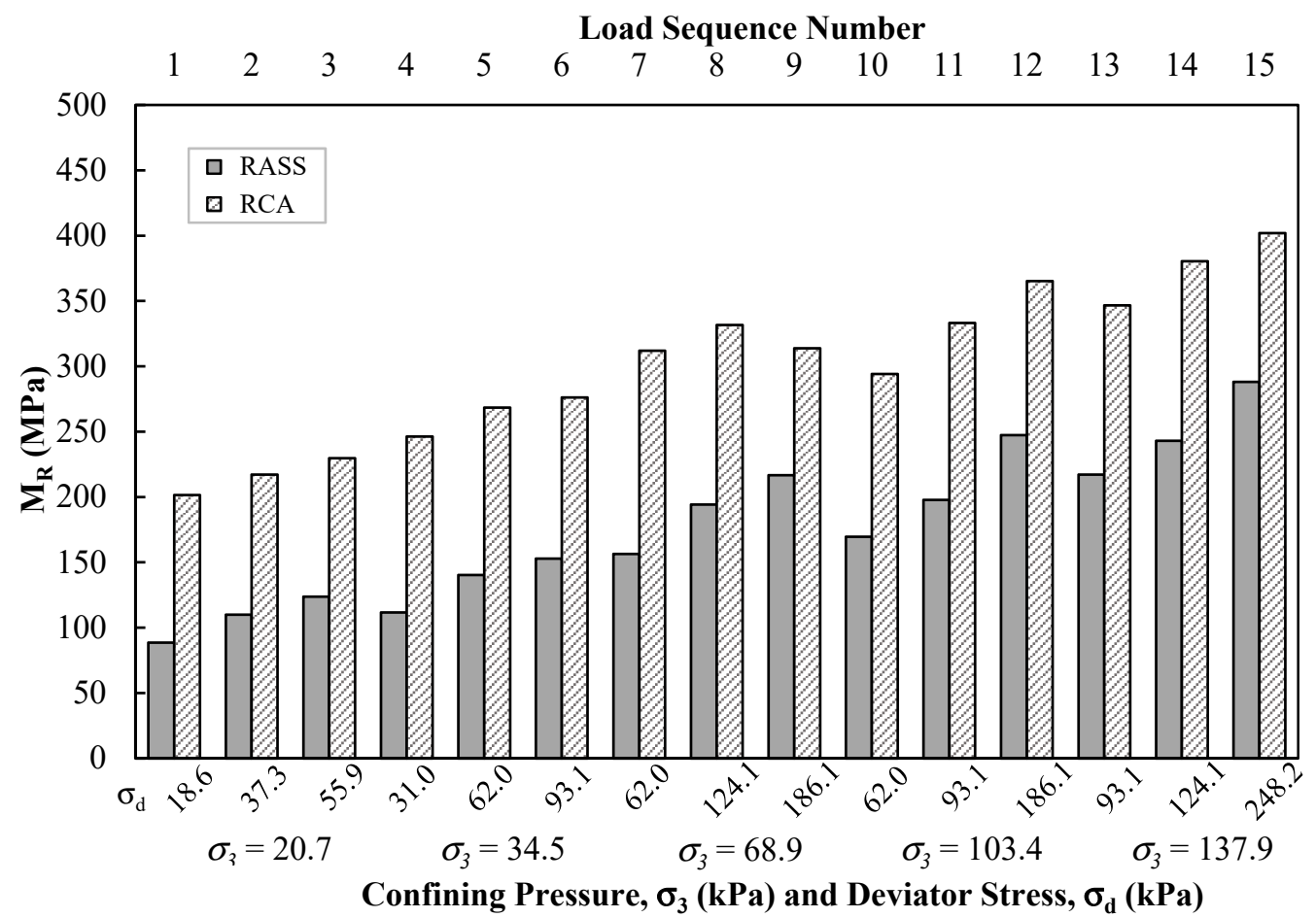

Figure 4. $\mathrm{M}_{\mathrm{R}}$ of RASS and RCA at different confining pressures and deviator stresses.

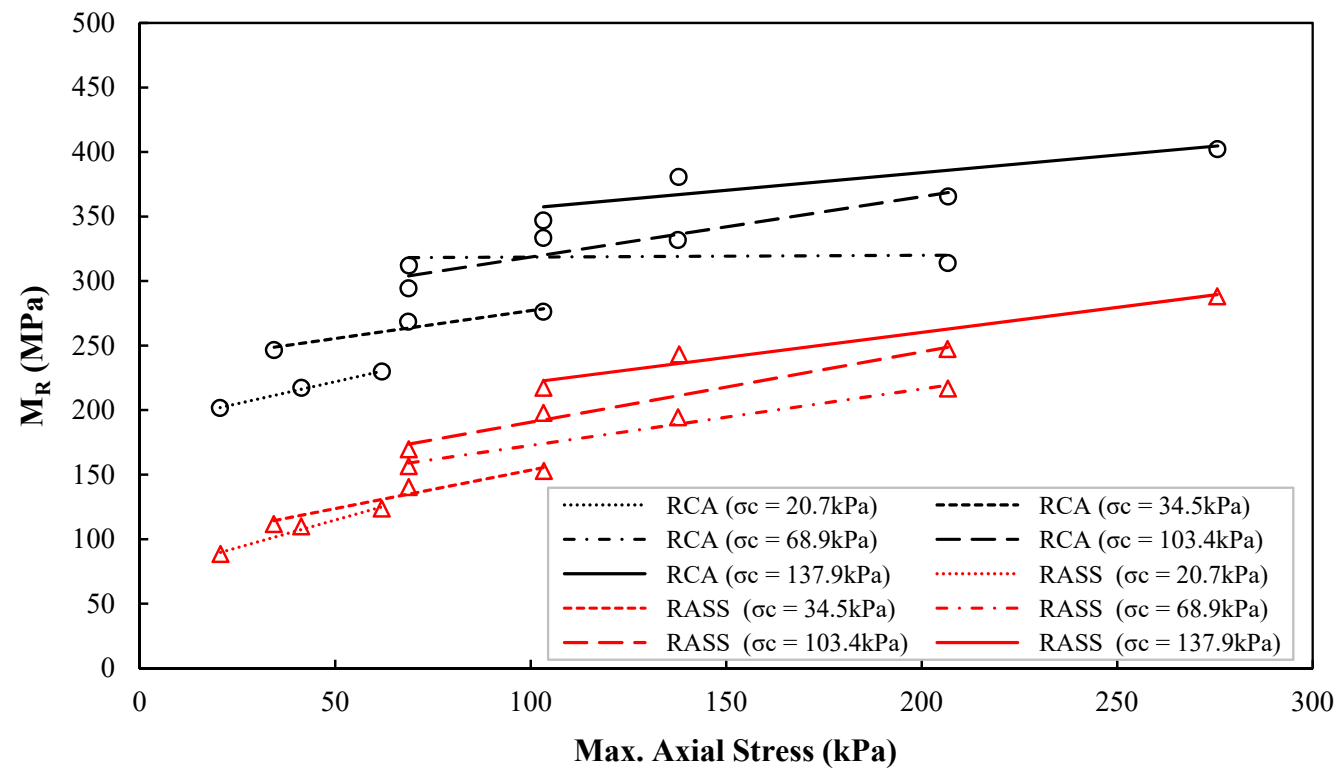

Figure 5. Influence of different axial stresses on the $M_{R}$ of RASS and RCA.

Apart from the above-mentioned findings, a slightly different trend was observed for the RCA sample at the ninth load sequence. A sudden drop in $M_{R}$ values of the RCA was observed at the ninth load sequence with applied deviator stress higher than the eighth load sequence under the same confinement, suggesting that granular sample does not always follow the stress hardening behavior under the aforementioned testing condition. 
A softening behavior can also occur on the granular sample, with increments in the deviator stress, whilst maintaining the same confining pressure. A similar phenomenon was also observed by Attia and Abdelrahman [53] for different C\&D recycled materials experiencing softening behavior with an increase in deviator stress under constant confinement. The range of the $M_{R}$ values of RASS and RCA are tabulated in Table 1. The $M_{R}$ values of the RCA were above the minimum requirements (125 MPa), specified by the local road authority for an unbound base and subbase material at all load sequences, whereas the $M_{R}$ value of the RASS was slightly below the limit at load sequences 1 to 4 [54]. Nevertheless, due to the superior hardness of the RASS, it is suggested that RASS can be blended with other well-graded recycled materials to overcome the limitation of RASS material, in terms of poor gradation, and further improve its resilient modulus response to a great extent.

According to the AASHTO test procedures, a two-parameter theta (bulk stress) regression model is recommended for the analysis of $M_{R}$ test results. The bulk stress model is expressed by the following equation [55]:

$$
M_{R}=k_{1} \times \theta^{k_{2}}
$$

The Equation (1) can be rearranged into a logarithmic form listed as:

$$
\log M_{R}=\log k_{1}+k_{2} \times \log \theta
$$

in which $\mathrm{M}_{\mathrm{R}}$ is the resilient modulus; $\theta=$ bulk stress $=\left(\sigma_{1}+\sigma_{2}+\sigma_{3}\right)=3 \sigma_{3}+\sigma_{d}$, representing the triaxial test conditions; $k_{1}$ and $k_{2}$ are the regression model parameter. The regression results of present tests for both materials are depicted in Figure 6. Table 2 demonstrates the regression model parameters, $\log k_{1}$ and $k_{2}$, as well as the coefficient of determination $R^{2}$. The $R^{2}$ values of the present resilient modulus tests were computed to be very close to 0.96 for both recycled materials, indicating that a good fit was achieved by employing the bulk stress model.

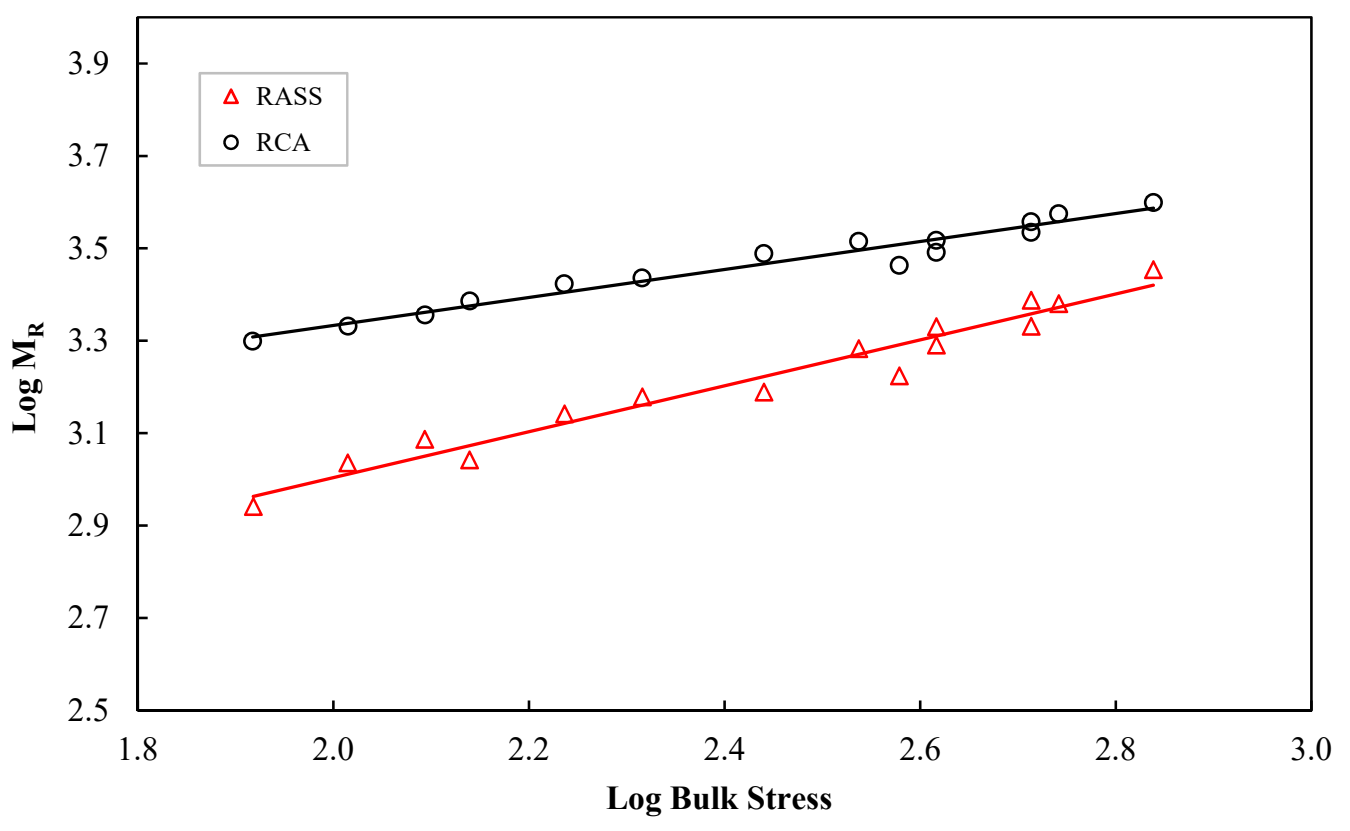

Figure 6. Bulk stress regression model of RASS and RCA.

Table 2. Regression parameters of bulk stress model.

\begin{tabular}{cccc}
\hline Material & $\log \boldsymbol{k}_{1}$ & $\boldsymbol{k}_{2}$ & Coefficient of Determination, $\boldsymbol{R}^{\mathbf{2}}$ \\
\hline RASS & 2.01 & 0.50 & 0.96 \\
RCA & 2.73 & 0.30 & 0.96 \\
\hline
\end{tabular}


Although the concise bulk stress model yields a reliable result, the major drawback of the bulk stress model is owing to the incapability of separating the influence of different confining pressures and deviator stresses on the corresponding $M_{R}$. A three-parameter theta model that takes into consideration both confining pressures and deviator stresses, proposed by Puppala et al. [52], was also used for the analysis of the present $\mathrm{M}_{\mathrm{R}}$ test results. The three-parameter theta model is given by:

$$
\frac{M_{R}}{\sigma_{a t m}}=k_{1}\left(\frac{\sigma_{3}}{\sigma_{a t m}}\right)^{k_{4}} \times\left(\frac{\sigma_{d}}{\sigma_{a t m}}\right)^{k_{5}}
$$

The logarithmic format of Equation (3) is described as:

$$
\log \left(\frac{M_{R}}{\sigma_{a t m}}\right)=\log k_{1}+k_{2} \log \left(\frac{\sigma_{3}}{\sigma_{a t m}}\right)+k_{3} \log \left(\frac{\sigma_{d}}{\sigma_{a t m}}\right)
$$

where $\sigma_{a t m}=$ atmospheric pressure; $\sigma_{3}=$ confining pressure; $\sigma_{d}=$ deviator stress; $\log k_{1}$, $k_{2}$ and $k_{3}$ are the regression constants of the three-parameter theta model. Table 3 lists the regression model constant and the coefficient of determination $R^{2}$. By comparing the results obtained from both regression models, the coefficient of determination, yielded by the three-parameter model, was higher than that of the bulk stress model, which is similar to the findings reported by Puppala et al. [52] and Mohammadinia et al. [56]. The consideration of the effects, induced by different confinement and deviator stresses on the $M_{R}$, produces a better fit and further enhances the accuracy of the results compared to the bulk stress model.

Table 3. Regression parameters of three-parameter model.

\begin{tabular}{ccccc}
\hline Material & $\mathbf{L o g} \boldsymbol{k}_{1}$ & $\boldsymbol{k}_{2}$ & $\boldsymbol{k}_{3}$ & Coefficient of Determination, $\boldsymbol{R}^{\mathbf{2}}$ \\
\hline RASS & 3.29 & 0.22 & 0.30 & 0.99 \\
RCA & 3.52 & 0.19 & 0.12 & 0.97 \\
\hline
\end{tabular}

\subsection{Environment Risks and Health Hazards}

In considering the usage of RASS as a geomaterial in civil construction, any possible environmental risks and health hazards, in terms of leaching hazards and exposure of contaminant constituents from such material into the soil, surrounding surface areas, and underground aquifers during its lifecycle in a project must be ascertained $[57,58]$. As per the EPA Victoria regulations, wastes need to be categorized into one of the following types: (a) fill material, typically made up of natural soil, sand, gravel, and rock, (b) solid inert waste, comprised of industrial and municipal wastes, such as industrial by-products and construction wastes (the RASS used in this research seems to fall into this category based on its source and production method), (c) putrescible waste that can be decomposed by bacteria activities, and (d) prescribed industrial waste that could have adverse effects on the environment and human health, sourced from manufacturing sectors or contaminated soils [43]. The assessments to determine the existence of contaminant constituents of the wastes are required before the wastes can be recycled, reused, and disposed in a landfill. The hazard categorization of the RASS sample was evaluated as per the guidelines recommended by the EPA Victoria and the Australian Standard Leaching Procedure (ASLP) [43]. The total contaminant (TC) and leachate concentration tests were carried out on the RASS to identify the presence of any possible contaminant constituents from such material. According to AS 4439.3-1997 [42], an appropriate type of leaching fluid, used for the leaching analysis on the material, should be determined based on the field application of the tested material. The kinds of leaching fluids recommended for conducting the leaching analysis on material, as per AS 4439.3-1997 [42], include reagent water and three other leaching fluids with a different $\mathrm{pH}$ value of 2.9, 5.0, and 9.2. Since the aim of this research is to evaluate the suitability of utilizing RASS as a geomaterial in applications such as pavement 
base/subbase material and embankment fills, reagent water that resembles rainwater seems to be the most suitable leaching fluid for such material. However, it should be noted that there is a possibility of acid rain $(\mathrm{pH} 3.6-4.9)$ resulting from the presence of organic acids in the atmosphere [59]. Graham [59] states that such organic acids are formed in the atmosphere by the photochemistry of organic compounds volatilized from terrestrial vegetation. In addition, the possible occurrence of acidic freshwater ( $\mathrm{pH} 4.0-5.5)$, in the first flush at the start of the wet season, should also be considered for determining the suitable leaching fluid [59]. According to the National Land and Water Resources Audit [60], about 50 million hectares of Australian agricultural land has a surface $\mathrm{pH}$ of 4.3-5.5, which implies the possible occurrence of acidic freshwater in the first flush of the wet season.

With these considerations in mind, it is safer to use a slightly acidic leaching fluid ( $\mathrm{pH}$ 5.0), based on the field application of RASS, rather than a reagent water. Furthermore, take into consideration that RASS could be utilized in blend with other types of recycled materials such as crushed brick, crushed concrete aggregate, and reclaimed asphalt pavement aggregate to meet specific engineering requirements for various applications. There is a possibility for RASS to be exposed to a slightly alkaline environment throughout its service life as a geomaterial. By considering all the aspects, a slightly acidic and alkaline leaching fluid with a $\mathrm{pH}$ value of 5.0 and 9.2 were selected to be used for the leachate analysis of the RASS. The leachate was prepared in line with the procedures described in the AS 4439.3-1997 [42]. The results of TC and ASLP values of RASS were compared with the limits set by EPA Victoria and EPA USA to ascertain the environmental risks and health hazards of utilizing RASS as a sustainable geomaterial [43-45]. Since RCA's leachate analysis was reported in the previous study, the leachability test of RCA was not repeated in this research [54].

The total contaminant and leachate concentration test results of RASS, illustrated in Table 4, were compared to the threshold values of TC and ASLP of fill material, solid inert waste, and drinking water standards specified by the EPA Victoria and EPA USA, manifested in Table 5. The TC values of the RASS were found to be far below the threshold values of fill material demanded by the EPA Victoria, suggesting that RASS falls into the category of fill material, as per the requirements recommended by the EPA Victoria. Such material can be safely utilized as fill material in geotechnical applications such as the construction of stone column for ground improvement, pavement layers, and embankment fill. The leachate concentration test results of RASS, expressed as TC and ASLP values, by use of both acidic and alkaline leaching fluid listed in Table 4 were, again, confirmed to be much lower than the acceptable values of solid inert waste according to the EPA Victoria specifications. The comparison implies that the environmental risks and health hazards concerning the exposure of contaminant constituents from such material into the soil, surrounding surface areas, and underground aquifers throughout its service life as a geotechnical construction material are negligible. Furthermore, based on the EPA USA specifications, wastes are classified as hazardous material if one's heavy metal content was detected at a concentration 100 times higher than the acceptable values of drinking water standards (illustrated in Table 5) specified by the EPA USA. By following this criterion, the ASLP values (both acidic and alkaline) of the RASS were also confirmed to satisfy the limit recommended by the EPA USA. Thus, the comparison indicates that RASS will not pose any environmental risks to the surface water stream or underground aquifer and is safe to use as a construction material in geotechnical applications. 
Table 4. TC and ASLP test results of RASS and RCA.

\begin{tabular}{ccccccc}
\hline & \multicolumn{3}{c}{ RASS } & \multicolumn{3}{c}{ RCA $^{\mathbf{c}}$} \\
\cline { 2 - 7 } Contaminant & TC $^{\mathbf{a}}$ & $\begin{array}{c}\mathbf{A S L P}^{\mathbf{b}} \\
\text { (Acetate) }\end{array}$ & $\begin{array}{c}\text { ASLP } \\
\text { (Tetraborate) }\end{array}$ & TC $^{\mathbf{a}}$ & $\begin{array}{c}\text { ASLP }^{\mathbf{b}} \\
\text { (Acetate) }\end{array}$ & $\begin{array}{c}\text { ASLP }^{\mathbf{b}} \\
\text { (Tetraborate) }\end{array}$ \\
\cline { 2 - 7 } Arsenic & $<0.01$ & $<0.01$ & 0.05 & $<5$ & $<0.01$ & $<0.1$ \\
Barium & $\mathrm{N} / \mathrm{A}$ & $\mathrm{N} / \mathrm{A}$ & $\mathrm{N} / \mathrm{A}$ & 88 & 0.34 & $<0.1$ \\
Cadmium & $<0.01$ & $<0.01$ & $<0.01$ & $<0.2$ & $<0.002$ & $<0.02$ \\
Chromium & 0.06 & 0.01 & 0.03 & 15 & 0.05 & $<0.1$ \\
Copper & 0.02 & 0.03 & 0.05 & $\mathrm{~N} / \mathrm{A}$ & $\mathrm{N} / \mathrm{A}$ & $\mathrm{N} / \mathrm{A}$ \\
Lead & 0.11 & 0.10 & $<0.01$ & 11 & $<0.01$ & $<0.1$ \\
Mercury & $<0.005$ & $<0.001$ & $<0.005$ & $<0.05$ & $<0.001$ & $<0.01$ \\
Selenium & $\mathrm{N} / \mathrm{A}$ & $\mathrm{N} / \mathrm{A}$ & $\mathrm{N} / \mathrm{A}$ & $<3$ & $<0.01$ & $<0.1$ \\
Silver & $\mathrm{N} / \mathrm{A}$ & $\mathrm{N} / \mathrm{A}$ & $\mathrm{N} / \mathrm{A}$ & $<5$ & $<0.01$ & $<0.1$ \\
Nickel & 0.06 & 0.02 & $<0.01$ & $\mathrm{~N} / \mathrm{A}$ & $\mathrm{N} / \mathrm{A}$ & $\mathrm{N} / \mathrm{A}$ \\
Zinc & 0.46 & 0.18 & 0.02 & $\mathrm{~N} / \mathrm{A}$ & $\mathrm{N} / \mathrm{A}$ & $\mathrm{N} / \mathrm{A}$ \\
Cyanide & $<0.25$ & $<0.25$ & $<0.25$ & $\mathrm{~N} / \mathrm{A}$ & $\mathrm{N} / \mathrm{A}$ & $\mathrm{N} / \mathrm{A}$ \\
PAH & $<0.001$ & $<0.001$ & $<0.001$ & $\mathrm{~N} / \mathrm{A}$ & $\mathrm{N} / \mathrm{A}$ & $\mathrm{N} / \mathrm{A}$ \\
\hline
\end{tabular}

${ }^{\mathrm{a}} \mathrm{mg} / \mathrm{kg}$ of dry weight. ${ }^{\mathrm{b}} \mathrm{mg} / \mathrm{L}^{\mathrm{c}}{ }^{\mathrm{c}}$ Data from Arulrajah et al. [54]. N/A: Not available. PAH: Polycyclic aromatic hydrocarbons.

Table 5. EPA Victoria and EPA USA requirements.

\begin{tabular}{ccccc}
\hline Contaminant & $\begin{array}{c}\text { Maximum TC } \\
\text { Allowed for Fill } \\
\text { Material }\end{array}$ & $\begin{array}{c}\text { Allowable TC and ASLP } \\
\text { Value for Solid Inert Waste }\end{array}$ & $\begin{array}{c}\text { US EPA Drinking } \\
\text { Water Standard } \mathbf{b}, \mathbf{e}\end{array}$ \\
\cline { 2 - 3 } & TC $^{\mathbf{a}, \mathbf{c}}$ & TC $^{\mathbf{a}, \mathbf{d}}$ & ASLP & \\
Arsenic & 20 & 500 & 0.35 & 0.05 \\
Barium & $\mathrm{N} / \mathrm{A}$ & 6250 & 35 & 2.0 \\
Cadmium & 3 & 100 & 0.1 & 0.005 \\
Chromium & 1 (Chromium VI) & 500 & 2.5 & 0.1 \\
Copper & 100 & 5000 & 100 & 1.3 \\
Lead & 300 & 1500 & 0.5 & 0.015 \\
Mercury & 1 & 75 & 0.05 & 0.002 \\
Selenium & 10 & 50 & 0.5 & 0.05 \\
Silver & 10 & 180 & 5 & 0.05 \\
Nickel & 60 & 3000 & 1 & N/A \\
Zinc & 200 & 35,000 & 150 & N/A \\
Cyanide & 50 & 2500 & 4 & N/A \\
PAH & 20 & 50 & N/A & N/A \\
\hline
\end{tabular}

$\overline{\mathrm{a}} \mathrm{mg} / \mathrm{kg}$ of dry weight. ${ }^{\mathrm{b}} \mathrm{mg} / \mathrm{L} .{ }^{\mathrm{c}}$ EPA Victoria [43]. ${ }^{\mathrm{d}}$ EPA Victoria [44]. N/A: Not available. PAH: Polycyclic aromatic hydrocarbons. ${ }^{\mathrm{e}}$ EPA USA [45].

\section{Conclusions}

The geotechnical and environmental characteristics of RASS were investigated, in this research, to fill the knowledge gap on the feasibility of utilizing such aluminum industrial waste by-products as sustainable geomaterials. The following conclusion can be drawn based on the laboratory testing results:

1 The RASS was classified as a poorly-graded material, due to the insufficient fine fraction, and the $\mathrm{pH}$ value of RASS was found to be slightly alkaline. The particle density of RASS was slightly higher that of RCA, whereas the water absorption of RASS was lower than that of the RCA. In addition, the RASS was also confirmed to be free-draining, cohesionless, and exhibited a very low organic content.

2 The RASS exhibited much higher stiffness compared to the RCA, based on the experimental outcomes of AIV and LA abrasion loss tests. The test results of flakiness index, LA abrasion loss, and CBR value of the RASS samples satisfy the requirements specified by the local road authority for usage as a pavement base and subbase material in road construction. 
3 The $M_{R}$ values of the RASS were found to be lower than those of the RCA and are slightly below the minimum $\mathrm{M}_{\mathrm{R}}$ requirement (125 MPa) recommended by the local road authority, Victoria, for an unbound base/subbase material, at load sequences 1 to 4 , under triaxial test conditions. The reasons contributing to the lower $M_{R}$ values of the RASS is mainly owing to the poor gradation of RASS material, which weakens the particle interlocking performance and the sensitivity of resilient modulus response of the tested granular samples, due to the reduction in the contact area between the particles. Considering the superior stiffness of RASS, it is suggested that RASS can be blended with other well-graded recycled materials, RCA for instance, to overcome the limitation in terms of its poor gradation and further enhance the $M_{R}$ value of the RASS significantly.

4 The results of the total contaminant and leachate concentration tests have shown that TC and ASLP values of RASS are far below the threshold values of fill material and solid inert waste specified by the EPA Victoria. This suggests that RASS can be safely employed as a geotechnical construction material and cause no harm to the surrounding environment. Furthermore, the ASLP values of the RASS are also within the acceptable limits of drinking water standards, according to the EPA USA specifications, indicating that RASS will not pose any health hazards by contaminating the surface water stream or underground aquifer.

In this research, the comparison between RASS and RCA provides satisfactory evidence that RASS possesses the capability to be utilized as a sustainable geomaterial in civil construction. However, it should be noted that the quality of the aluminum industrial by-product, RASS, is dependent on the machinery used and manufacturing technique. In developing countries, where manufacturing technique and equipment are outdated, the percentage of unmelted aluminum products (such as nails, screws, and residual parts of beverage cans) in the RASS stockpile could be various, which will result in fluctuating in the overall geotechnical properties of such recycled material. Geotechnical and engineering assessment should be performed on the RASS sample from a stockpile before utilizing the RASS in geotechnical applications. The research outcomes of this study can be used as guidance, assisting relevant bodies in comparing the required geotechnical and engineering parameters, and determining the suitability of a RASS stockpile to be utilized in geotechnical applications. It is also recommended that future research can focus on the stabilization of RASS by introducing additive binders, such as cement or alkali-activated cementitious material, to further strengthen the mechanical performance of RASS and widen its applications in geotechnical construction. The usage of RASS as a sustainable geomaterial in civil construction provides a feasible end-of-life option to convert the aluminum industrial waste from landfill into a usable material, mitigate the pressure on land and natural resources, as well as improve sustainability in the civil construction industry.

Author Contributions: Conceptualization: Y.L., F.M., A.A. and S.H.; methodology: Y.L.; formal analysis: Y.L.; writing—original draft preparation: Y.L.; writing—review and editing: F.M., A.A. and S.H.; supervision: F.M. and A.A.; funding acquisition: F.M., A.A. and S.H. All authors have read and agreed to the published version of the manuscript.

Funding: This research was funded by the SmartCrete CRC Ltd. (Macquarie Park, Australia).

Institutional Review Board Statement: Not applicable.

Informed Consent Statement: Not applicable.

Data Availability Statement: The data presented in this study are available on request from the corresponding author. The data are not publicly available due to privacy restrictions.

Acknowledgments: The authors are grateful for the financial support provided by the SmartCrete CRC Ltd. and the industry partners (Hawks Excavation Pty Ltd. (Doncaster East, Australia), Stretford Civil Constructions Pty Ltd. (Balwyn North, Australia)) for conducting this research project.

Conflicts of Interest: The authors declare no conflict of interest. 


\section{References}

1. Li, C.Z.; Zhao, Y.; Xiao, B.; Yu, B.; Tam, V.W.; Chen, Z.; Ya, Y. Research trend of the application of information technologies in construction and demolition waste management. J. Clean. Prod. 2020, 263, 121458. [CrossRef]

2. Akhtar, A.; Sarmah, A.K. Construction and demolition waste generation and properties of recycled aggregate concrete: A global perspective. J. Clean. Prod. 2018, 186, 262-281. [CrossRef]

3. Silva, R.; De Brito, J.; Dhir, R. Use of recycled aggregates arising from construction and demolition waste in new construction applications. J. Clean. Prod. 2019, 236, 117629. [CrossRef]

4. McKelvey, D.; Sivakumar, V.; Bell, A.; McLaverty, G. Shear strength of recycled construction materials intended for use in vibro ground improvement. Proc. Inst. Civ. Eng.-Ground Improv. 2002, 6, 59-68. [CrossRef]

5. Vieira, C.S.; Pereira, P.M. Use of recycled construction and demolition materials in geotechnical applications: A review. Resour. Conserv. Recycl. 2015, 103, 192-204. [CrossRef]

6. Henzinger, C.; Heyer, D. Soil improvement using recycled aggregates from demolition waste. Proc. Inst. Civ. Eng.-Ground Improv. 2018, 171, 74-81. [CrossRef]

7. Brooks, R.; Cetin, M. Application of construction demolition waste for improving performance of subgrade and subbase layers. Int. J. Res. Rev. Appl. Sci. 2012, 12, 375.

8. Yi, Y.; Gu, L.; Liu, S.; Puppala, A.J. Carbide slag-Activated ground granulated blastfurnace slag for soft clay stabilization. Can. Geotech. J. 2015, 52, 656-663. [CrossRef]

9. Imteaz, M.A.; Arulrajah, A.; Maghool, F. Environmental and geotechnical suitability of recycling waste materials from plasterboard manufacturing. Waste Manag. Res. 2020, 38, 383-391. [CrossRef] [PubMed]

10. Maghool, F.; Arulrajah, A.; Suksiripattanapong, C.; Horpibulsuk, S.; Mohajerani, A. Geotechnical properties of steel slag aggregates: Shear strength and stiffness. Soils Found. 2019, 59, 1591-1601. [CrossRef]

11. Prem, P.R.; Verma, M.; Ambily, P. Sustainable cleaner production of concrete with high volume copper slag. J. Clean. Prod. 2018, 193, 43-58. [CrossRef]

12. International Aluminium Institute. Primary Aluminium Production Statistics Report. 2021. Available online: https://www. world-aluminium.org/statistics / (accessed on 10 March 2021).

13. Shinzato, M.; Hypolito, R. Solid waste from aluminum recycling process: Characterization and reuse of its economically valuable constituents. Waste Manag. 2005, 25, 37-46. [CrossRef]

14. Gil, A.; Korili, S. Management and valorization of aluminum saline slags: Current status and future trends. Chem. Eng. J. 2016, 289, 74-84. [CrossRef]

15. Adeosun, S.O.; Sekunowo, O.I.; Taiwo, O.O.; Ayoola, W.A.; Machado, A. Physical and Mechanical Properties of Aluminum Dross. Adv. Mater. 2014, 3, 6-10. [CrossRef]

16. Mahinroosta, M.; Allahverdi, A. Hazardous aluminum dross characterization and recycling strategies: A critical review. J. Environ. Manag. 2018, 223, 452-468. [CrossRef]

17. Karvelas, D.; Daniels, E.; Jody, B.; Bonsignore, P. An Economic and Technical Assessment of Black-Dross and Salt-Cake-Recycling Systems for Application in the Secondary Aluminum Industry; Argonne National Lab., Energy Systems Div.: Chicago, IL, USA, 1991.

18. Dai, C. Development of Aluminum Dross-Based Material for Engineering Application. Master's Thesis, Worcester Polytechnic Institute, Worcester, MA, USA, January 2012.

19. Ozerkan, N.; Maki, O.; Anayeh, M.; Tangen, S.; M Abdullah, A. The effect of aluminium dross on mechanical and corrosion properties of concrete. Int. J. Innov. Res. Sci. 2014, 3, 9912-9922.

20. Pereira, D.; de Aguiar, B.; Castro, F.; Almeida, M.; Labrincha, J. Mechanical behaviour of Portland cement mortars with incorporation of Al-containing salt slags. Cem. Concr. Res. 2000, 30, 1131-1138. [CrossRef]

21. Reddy, M.S.; Neeraja, D. Mechanical and durability aspects of concrete incorporating secondary aluminium slag. Resour.-Effic. Technol. 2016, 2, 225-232. [CrossRef]

22. Reddy, M.S.; Neeraja, D. Aluminum residue waste for possible utilisation as a material: A review. Sādhanā 2018, 43, 124. [CrossRef]

23. Dunster, A.; Moulinier, F.; Abbott, B.; Conroy, A.; Adams, K.; Widyatmoko, D. Added Value of Using New Industrial Waste Streams as Secondary Aggregates in both Concrete and Asphalt; The Waste \& Resources Action Programme: Banbury, UK, 2005.

24. López-Alonso, M.; Martinez-Echevarria, M.; Garach, L.; Galán, A.; Ordoñez, J.; Agrela, F. Feasible use of recycled alumina combined with recycled aggregates in road construction. Constr. Build. Mater. 2019, 195, 249-257. [CrossRef]

25. Busari, A.A.; Akinwumi, I.; Awoyera, P.O.; Olofinnade, O.; Tenebe, T.; Nwanchukwu, J. In Stabilization effect of aluminum dross on tropical lateritic soil, International Journal of Engineering Research in Africa. Trans. Tech. Publ. 2018, 39, 86-96.

26. Gayatri, A.; Verma, A.K. Geotechnical Characterization of Expansive Soil and Utilization of Waste to Control Its Swelling and Shrinkage Behaviour. In Recent Developments in Waste Management; Springer: Singapore, 2020; pp. 11-21. [CrossRef]

27. ASTM D75/D75M-19. Standard Practice for Sampling Aggregates; ASTM International: West Conshohocken, PA, USA, 2014.

28. AS 1141.11. Method for Sampling and Testing Aggregates Method 11: Particle Size Distribution by Sieving; Standards Australia: Sydney, Australia, 2020.

29. ASTM D2487-17. Standard Practice for Classification of Soils for Engineering Purposes (Unified Soil Classification System); ASTM International: West Conshohocken, PA, USA, 2020.

30. BS 812-105.1. Method for Determination of Particle Shape; Flakiness Index; British Standards Institution: London, UK, 2000. 
31. ASTM D2974. Standard Test Methods for Moisture, Ash, and Organic Matter of Peat and other Organic Soils; ASTM International: West Conshohocken, PA, USA, 2007.

32. AS 1289.4.3.1. Soil Chemical Tests-Determination of the $p H$ Value of a Soil-Electrometric Method; Standards Australia: Sydney, Australia, 1997.

33. AS 1141.5. Particle Density and Water Absorption of fine Aggregate; Standards Australia: Sydney, Australia, 2000.

34. AS 1141.6.1. Particle Density and Water Absorption of Coarse Aggregate-Weighing-in-Water Method; Standards Australia: Sydney, Australia, 2000.

35. AS 1289.5.2.1. Soil Compaction and Density Tests-Determination of the Dry Density/Moisture Content Relation of a Soil Using Modified Compactive Effort; Standards Australia: Sydney, Australia, 2003.

36. BS 812-112. Testing Aggregates-Part 112: Methods for Determination of Aggregate Impact Value (AIV); British Standards Institution: London, UK, 1990.

37. ASTM C131. Standard Test Method for Resistance to Degradation of Small-Size Coarse Aggregate by Abrasion and Impact in the Los Angeles Machine; ASTM International: West Conshohocken, PA, USA, 2006.

38. AS 1289.6.7.1. Methods of Testing Soils for Engineering Purposes-Soil Strength and Consolidation Tests-Determination of Permeability of a Soil-Constant Head Method for a Remoulded Specimen; Standards Australia: Sydney, Australia, 2001.

39. AS 1289.6.7.2. Methods of Testing Soils for Engineering Purposes-Soil Strength and Consolidation Tests-Determination of Permeability of a Soil-Falling Head Method for a Remoulded Specimen; Standards Australia: Sydney, Australia, 2001.

40. ASTM D1883. Standard Test Method for CBR (California Bearing Ratio) of Laboratory-Compacted Soils; ASTM International: West Conshohocken, PA, USA, 2007.

41. AASHTO T 307-99. Standard Method of test for Determining the Resilient Modulus of Soils and Aggregate Materials; American Association of State Highway and Transportation Officials: Washington, DC, USA, 2007.

42. AS 4439.3. Wastes, Sediments and Contaminated Soils, Part 3: Preparation of Leachates-Bottle Leaching Procedure; Standards Australia: Sydney, Australia, 1997.

43. EPA Victoria. Waste Categorization, Industrial Waste Resource Guidelines; Environmental Protection Agency of Victoria: Melbourne, Australia, 2010.

44. EPA Victoria. Solid Industrial Waste Hazard Categorization and Management, Industrial Waste Resource Guidelines; Environmental Protection Agency of Victoria: Melbourne, Australia, 2009.

45. U.S. EPA. National Primary Drinking Water Standards; Environmental Protection Agency: Washington, DC, USA, 1999.

46. VicRoads. Registration of Crushed Rock Mixes, Code of Practice RC 500.02; VicRoads: Melbourne, Australia, 2017.

47. Arulrajah, A.; Piratheepan, J.; Ali, M.; Bo, M. Geotechnical properties of recycled concrete aggregate in pavement sub-base applications. Geotech. Test. J. 2012, 35, 743-751. [CrossRef]

48. Lekarp, F.; Isacsson, U.; Dawson, A. State of the art. I: Resilient response of unbound aggregates. J. Transp. Eng. 2000, 126, 66-75.

49. Maghool, F.; Arulrajah, A.; Horpibulsuk, S.; Du, Y.-J. Laboratory evaluation of ladle furnace slag in unbound pavementbase/subbase applications. J. Mater. Civ. Eng. 2017, 29, 04016197. [CrossRef]

50. Yaghoubi, E.; Sudarsanan, N.; Arulrajah, A. Stress-strain response analysis of demolition wastes as aggregate base course of pavements. Transp. Geotech. 2021, 30, 100599. [CrossRef]

51. Zhang, J.; Gu, F.; Zhang, Y. Use of building-related construction and demolition wastes in highway embankment: Laboratory and field evaluations. J. Clean. Prod. 2019, 230, 1051-1060. [CrossRef]

52. Puppala, A.J.; Hoyos, L.R.; Potturi, A.K. Resilient moduli response of moderately cement-treated reclaimed asphalt pavement aggregates. J. Mater. Civ. Eng. 2011, 23, 990-998. [CrossRef]

53. Attia, M.; Abdelrahman, M. Effect of state of stress on the resilient modulus of base layer containing reclaimed asphalt pavement. Road Mater. Pavement Des. 2011, 12, 79-97. [CrossRef]

54. Arulrajah, A.; Piratheepan, J.; Disfani, M.M.; Bo, M.W. Geotechnical and geoenvironmental properties of recycled construction and demolition materials in pavement subbase applications. J. Mater. Civ. Eng. 2013, 25, 1077-1088. [CrossRef]

55. AASHTO. Guide for Design of Pavement Structures; American Association of State Highway and Transportation Officials: Washington, DC, USA, 1993.

56. Mohammadinia, A.; Arulrajah, A.; Sanjayan, J.; Disfani, M.M.; Bo, M.W.; Darmawan, S. Laboratory evaluation of the use of cement-treated construction and demolition materials in pavement base and subbase applications. J. Mater. Civ. Eng. 2015, 27, 04014186. [CrossRef]

57. Disfani, M.; Arulrajah, A.; Bo, M.; Sivakugan, N. Environmental risks of using recycled crushed glass in road applications. J. Clean. Prod. 2012, 20, 170-179. [CrossRef]

58. Kua, T.-A.; Imteaz, M.A.; Arulrajah, A.; Horpibulsuk, S. Environmental and economic viability of Alkali Activated Material (AAM) comprising slag, fly ash and spent coffee ground. Int. J. Sustain. Eng. 2019, 12, 223-232. [CrossRef]

59. Graham, P. Current waste soil disposal practices in NSW. In Proceedings of the SuperSoil 2004, 3rd Australian New Zealand Soils Conference, Sydney, Australia, 5-9 December 2004.

60. National Land and Water Resources Audit. Australian Agriculture Assessment 2001; Australian Government, Land \& Water Australia: Canberra, Australia, 2001. 